\title{
BMJ Open Platelet aggregation inhibitor prescription for newly diagnosed peripheral arterial disease in the Netherlands: a cohort study
}

Aarent RT Brand (D) , ${ }^{1}$ Eline Houben (D) , ${ }^{2}$ Irene D Bezemer, ${ }^{2}$ Frank L J Visseren (D) , ${ }^{3}$ Michiel L Bots, ${ }^{4}$ Ron MC Herings, ${ }^{2,5}$ Gert J de Borst ${ }^{1}$

To cite: Brand ART, Houben E, Bezemer ID, et al. Platelet aggregation inhibitor prescription for newly diagnosed peripheral arterial disease in the Netherlands: a cohort study. BMJ Open 2021;11:e041715. doi:10.1136/ bmjopen-2020-041715

- Prepublication history and additional material for this paper are available online. To view these files, please visit the journal online (http://dx.doi. org/10.1136/bmjopen-2020041715).

Received 11 August 2020 Revised 07 December 2020 Accepted 14 December 2020

Check for updates

(C) Author(s) (or their employer(s)) 2021. Re-use permitted under CC BY-NC. No commercial re-use. See rights and permissions. Published by BMJ.

For numbered affiliations see end of article.

Correspondence to Dr Gert J de Borst, Vascular Surgery, University Medical Center Utrecht, Utrecht, Utrecht, The Netherlands;

G.J.deBorst-2@umcutrecht.nl

\section{ABSTRACT}

Objectives Pharmacological treatment of peripheral arterial disease (PAD) comprises of antiplatelet therapy (APT), blood pressure control and cholesterol optimisation. Guidelines provide class-I recommendations on the prescription, but there are little data on the actual prescription practices. Our study provides insight into the prescription of medication among patients with PAD in the Netherlands and reports a 'real-world' patient journey through primary and secondary care.

Design We conducted a cohort study among patients newly diagnosed with PAD between 2010 and 2014. Setting Data were obtained from the PHARMO Database Network, a population-based network of electronic pharmacy, primary and secondary healthcare setting records in the Netherlands. The source population for this study comprised almost 1 million individuals.

Participants 'Newly diagnosed' was defined as a recorded International Classification of Primary Care code for PAD, a PAD-specific WCIA examination code or a diagnosis recorded as free text episode in the general practitioner records with no previous PAD diagnosis record and no prescription of $\mathrm{P} 2 \mathrm{Y} 12$ inhibitors or aspirin the preceding year. The patient journey was defined by at least 1 year of database history and follow-up relative to the index date.

Results Between 2010 and 2014, we identified 3677 newly diagnosed patients with PAD. Most patients (91\%) were diagnosed in primary care. Almost half of all patients (49\%) had no APT dispensing record. Within this group, $33 \%$ received other anticoagulant therapy (vitamin $\mathrm{K}$ antagonist or direct oral anticoagulant). Mono-APT was dispensed as aspirin ( $40 \%$ of patients) or P2Y12 inhibitors ( $2.5 \%$ of patients). Dual APT combining aspirin with a P2Y12 inhibitor was dispensed to $8.5 \%$ of the study population.

Conclusion Half of all patients with newly diagnosed PAD are not treated conforming to (international) guideline recommendations on thromboembolism prevention through APT. At least $33 \%$ of all patients with newly diagnosed PAD do not receive any antithrombotic therapy. Evaluation and improvement of APT prescription and thereby improved prevention of (secondary) cardiovascular events is warranted.
Strengths and limitations of this study

In this large cohort, data for almost 1 million patients were included.

- This is the first study to show patient flow and prescription patterns through primary and secondary care.

- This is the first study to provide insight into the reallife adherence to prescription guidelines for peripheral arterial disease.

- Strict exclusion criteria and data limitations might have caused an under-representation of newly diagnosed patients.

- Updates of guidelines might influence physicians' prescription patterns today.

\section{INTRODUCTION}

Peripheral arterial disease (PAD) is an invalidating chronic condition associated with increased cardiovascular morbidity and mortality. ${ }^{1-4}$ Progressive narrowing of the peripheral arteries prevents blood flow to the extremities, causing pain. This is called symptomatic PAD or intermittent claudication (IC). Guidelines define IC through a combination of clinical symptoms and an ankle-brachial index $\leq 0.9 .^{5-9}$ The end-stage of PAD, critical limb ischaemia (CLI), is characterised by severe resting pain, ulceration and tissue loss. These are all stages within the progression of PAD.

Between ages of 55 and 59 years, a prevalence of $11 \%-19 \%$ has been reported for PAD, rising to over $50 \%$ in ages $\geq 85$ years. ${ }^{10} 11$ Only one-third of all patients with PAD are assumed to have symptomatic PAD. ${ }^{11}{ }^{12}$ Despite a significant decrease in the risk of cardiovascular mortality over the past decades, symptomatic PAD still has a very high premature mortality rate. ${ }^{13}$ In the Netherlands, patients admitted to the hospital for CLI have a 5-year survival rate $<70 \%$, similar to the 5 -year risk of acute myocardial infarction. ${ }^{4}$ 
Management of symptomatic PAD includes symptom relief, walking therapy and medical treatment to reduce the risk of secondary cardiovascular events (CVEs). In the Netherlands, both general practitioners (GPs) and vascular specialists treat patients with PAD. Patients with PAD generally receive lipid-lowering drugs, antihypertensives and antiplatelet therapy (APT). The latter has been shown to reduce the risk of thrombotic complications. Guidelines all recommend APT to reduce the risk of future thromboembolic complications and CVE..$^{5-9}$ Low-dose aspirin monotherapy (50-325 mg daily) lowers the risk of secondary CVE (defined as non-fatal myocardial infarctions, non-fatal strokes or vascular deaths) with $23 \% .^{14}$ The CAPRIE trial found that the P2Y12 inhibitor clopidogrel had an additional risk reduction of $8.7 \%$ over aspirin (95\% CI $0.3 \%$ to $16.5 \%) .{ }^{15}$ Dual APT (DAPT) has been suggested to lower the thromboembolic risk further and increase the efficacy of APT in patients with symptomatic PAD, especially after revascularisation procedures, but otherwise, reviews have concluded that there is no benefit of DAPT over mono-APT in endovascular interventions in patients with PAD. ${ }^{16}$

To our knowledge, outside the boundaries of prospective but relatively outdated $(\leq 2007)$ patient cohorts, there are no current data on to what extent patients are treated according to guideline standards. Insight into timing, patient journey and type of APT prescriptions is therefore warranted. This study aimed to investigate the concordance of patient care with guideline recommendations on APT for patients with newly diagnosed PAD in the Netherlands.

\section{METHODS}

\section{Cohort description}

Data were obtained from the PHARMO Database Network (PHARMO) in the Netherlands. This population-based network of electronic healthcare databases combines data from primary and secondary healthcare in the Netherlands. These sources are linked on a patient level through validated probabilistic linkage algorithms. ${ }^{17} 18$ PHARMO comprehends a follow-up on more than 4 million ( 23\%) residents for an average of 10 years. We used the PHARMO General Practitioner Database (GPD), and the PHARMO Outpatient Pharmacy Database covering 951886 individuals in 2014. ${ }^{17}{ }^{18}$ Patients were not involved in this study.

The GPD contains electronic patient records from GPs, including information on diagnoses and symptoms, laboratory test results, referrals to specialists and healthcare product/drug prescriptions. Diagnoses and symptoms are coded according to the International Classification of Primary Care (ICPC), mapped to International Classification of Diseases codes or entered as free text. ${ }^{19} \mathrm{GP}$ examinations (laboratory and function tests) are coded according to the Dutch national standard coding system (Werkgroep Coordinatie Informatisering en Automatisering (WCIA)) of the Dutch National Association of
General Practitioners and The Dutch College of General Practitioners.

Drug dispenses are coded according to the WHO Anatomical Therapeutic Chemical (ATC) Classification System, ${ }^{20}$ and coded for information on product type, date, strength, dosage regimen, quantity, administration route, prescriber specialty and costs. All data were anonymised prior to data collection.

All patients with a recorded PAD ICPC code, a PADspecific WCIA code or a PAD diagnosis recorded as free text in the GP records from January 2010 to December 2014 were selected. The ICPC, WCIA codes and text mining terms are stated in online supplemental appendix 1. Patients were followed until December 2015, enabling a minimum 1 year of follow-up, requiring at least 365 days of database history before the index date. ATC codes were used to define recent APT treatment dispensing 31-365 days before the index date (online supplemental appendix).

The index date is defined as the first recorded PAD diagnosis during the study period. Each patient was followed from the index date until the end of data collection, death or end of the study period, whichever came first (figure 1).

Patient characteristics assessed on the index date are presented overall and by setting at the index date. The distinction between primary and secondary care setting at index date was based on the physician prescribing drugs, that is, GP or secondary care specialist (see online supplemental appendix for relevant ATC codes).

Different follow-up phases were defined: initiation of PAD treatment ( $\leq 3$ months), short-term maintenance therapy (3-12 months) and long-term maintenance therapy ( $\geq 12$ months after the index date). For each phase, the setting of care was defined by evaluating correspondence between a GP and a secondary care specialist (ie, referral letter), specialist-prescribed dispensing of APT or statins, or the indication/occurrence of revascularisation (by definition in secondary care) and defined as 'referral to secondary care'. The referral date to secondary care was defined as the date of the referral letter or first specialist-prescribed dispensing, whichever came first.

PAD treatment was initiated in primary care if the setting at the index date was primary or if there was a referral to a physiotherapist during the initiation phase. Patients were considered in secondary care if they were in secondary care at the index date or referred to secondary care during the initiation phase.

Return to primary care was defined by the absence of specialist-prescribed pharmacy dispensing during at least 9 months. The date of return was defined as the start date of these 9 months. Patients could switch to secondary care and return to primary care multiple times.

The flow of patients with PAD through primary and secondary care was constructed following patients over time: at index date, during initiation of treatment, shortterm maintenance therapy and long-term maintenance 


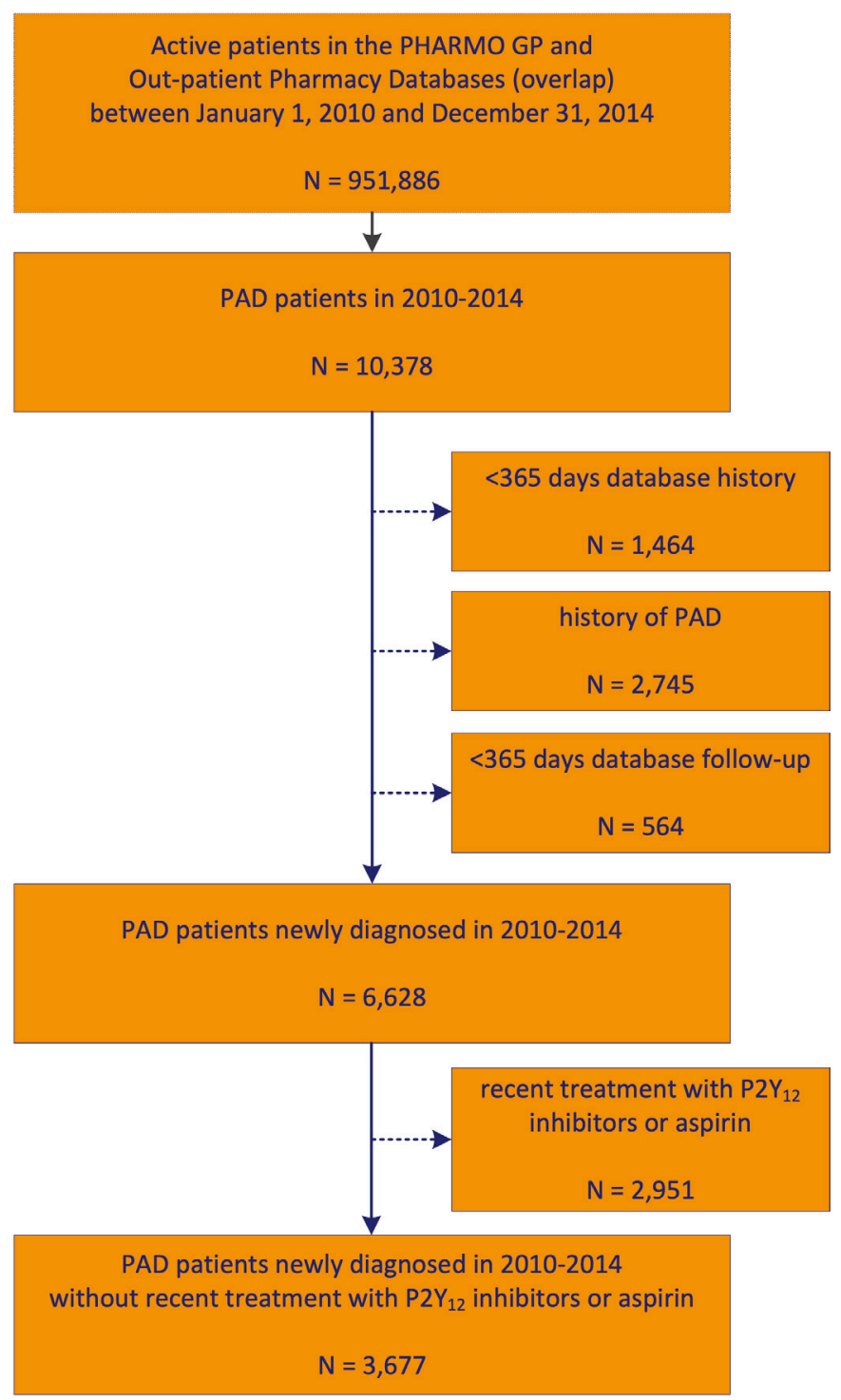

Figure 1 Patient selection. GP, general practitioner; PAD, peripheral arterial disease.

therapy. To put the events in the perspective of time, we assessed the time between index date and secondary care referral, revascularisation or return to primary care. The proportion of patients with revascularisation is presented in a Kaplan-Meier curve, censoring patients at revascularisation date and end of follow-up, respectively.

Revascularisation was assessed at any time after the index date (see online supplemental appendix). Outpatient pharmacy dispensing was assessed after the revascularisation date or, when no revascularisation was recorded, after the index date. The distribution of revascularisation and medication prescription is presented overall and by the timing of first referral (per follow-up phase).

The observed treatment strategies were compared with Dutch GP guidelines, ${ }^{5}$ the 2005 American College of Cardiology Foundation/American Heart Association guidelines for the management of patients with PAD and its update, ${ }^{69}$ the 2007 Inter-Society Consensus for the management of PAD (TASC II) guideline and the 2011
European Society of Cardiology (ESC) Guidelines on the diagnosis and treatment of PAD (table 1). ${ }^{78}$ These guidelines discuss various treatment strategies for PAD. Antiplatelet agents are either recommended as monotherapy or dual therapy. When direct oral anticoagulants (DOACs) or oral anticoagulants are prescribed, APT is usually temporarily interrupted or substituted with these medicines. To provide a comprehensive overview, we included all agents mentioned in the guidelines.

\section{Patient and public involvement}

Patients were not involved in this study.

Data extraction, variable definition, cohort selection, descriptive analysis and statistical analysis were performed using SAS programs (v9.4).

\section{RESULTS}

The source population contained 951886 patients between 2010 and 2014, of whom 10.378 (1\%) had a PAD diagnosis. Exclusion criteria were an earlier PAD diagnose, $<365$ days of database history or less than 1 year of follow-up. Insufficient follow-up was explained by death $(42 \%)$ or $<12$ months of follow-up because of the end of data collection (58\%). From the 6628 patients newly diagnosed with PAD, $44.5 \%$ were excluded because they had recently been prescribed APT (figure 1).

Of all 3677 patients included, $48 \%$ were women. The mean age was $67 \pm 12$ years. The mean database follow-up was 3.1 \pm 1.4 years. Most patients $(91 \%)$ were diagnosed in primary care. A history of cardiovascular or cerebrovascular disease within the preceding year was found in $11 \%$ and $10 \%$ of patients, respectively. Eight per cent had a history of acute coronary syndrome (ACS); more commonly in secondary care (16\% vs $7 \%$ ) (table 2$)$.

Less than $1 \%$ were referred to secondary care during the first 3 months. From the $9 \%$ in secondary care at the index date, $47 \%$ were referred to primary care during the first 3 months. After 3 months, $8.1 \%$ of patients in secondary care started short-term maintenance APT, and $39 \%$ returned to primary care within the first year. After 1 year, $17 \%$ were in secondary care for long-term APT or revascularisation. The proportion of patients referred back to primary care declined over time: $53 \%$ remained after initiation, $61 \%$ after 3 months therapy and $76 \%$ after 12 months (figure 2).

APT and statins were prescribed to $51 \%$ and $69 \%$ of all patients, respectively. Aspirin was dispensed as mono-APT to $40 \%$ of all patients, and $2.5 \%$ received $\mathrm{P} 2 \mathrm{Y} 12$ inhibitors as mono-APT. DAPT was dispensed to $8.5 \%$, mainly $(84 \%)$ as clopidogrel with aspirin (figure 3 ).

Remarkably, $49 \%$ had no APT dispensing at all, of whom 50\% received statins and 23\% was prescribed walking therapy. Circa one-third of patients not receiving APT were prescribed vitamin K antagonists (94\%) or DOACs $(6 \%)$. In total, $33 \%$ of all patients received neither adequate APT nor other anticoagulants (table 3). 


\begin{tabular}{|c|c|c|c|}
\hline Guideline & PAD diagnosis & Intermittent claudication & After revascularisation \\
\hline NHG $2003^{5}$ & $\begin{array}{l}\text { Smoking cessation } \\
\text { Optimisation of risk factors } \\
\text { Supervised walking therapy } \\
\text { Acetylsalicylic acid } 80 \mathrm{mg} \\
\text { daily }\end{array}$ & $\begin{array}{l}\text { Acetylsalicylic acid } 80 \mathrm{mg} \text { daily } \\
\text { Alternatively clopidogrel } 75 \mathrm{mg} \\
\text { daily }\end{array}$ & If indicated, oral anticoagulants \\
\hline $\begin{array}{l}\text { ACCF/AHA } \\
2011^{9}\end{array}$ & $\begin{array}{l}\text { Smoking cessation } \\
\text { Optimisation of risk factors } \\
\text { Supervised walking therapy } \\
\text { APT (level A) } \\
\text { Acetylsalicylic } 75-325 \mathrm{mg} \\
\text { daily }\end{array}$ & $\begin{array}{l}\text { Acetylsalicylic acid } 75-325 \mathrm{mg} \\
\text { daily } \\
\text { Alternatively clopidogrel } 75 \mathrm{mg} \\
\text { daily } \\
\text { No oral anticoagulation or } \\
\text { warfarin } \\
\text { DAPT (acetylsalicylic } \\
\text { acid+clopidogrel) can be } \\
\text { considered }\end{array}$ & Consider DAPT \\
\hline ESC $2011^{8}$ & $\begin{array}{l}\text { APT indicated } \\
\text { Acetylsalicylic } 75-150 \mathrm{mg} \\
\text { daily }\end{array}$ & $\begin{array}{l}\text { APT indicated } \\
\text { Acetylsalicylic } 75-150 \mathrm{mg} \text { daily } \\
\text { - No DAPT (bleeding risk) }\end{array}$ & $\begin{aligned} \text { - Acetylsalicylic acid. } \\
\text { Acetylsalicylic acid+thienopyridine } \\
\text { (BMS) } \\
\text { - Acetylsalicylic acid+dipyridamole (liBS) } \\
\text { Vitamin K inhibitors (liBS) } \\
\text { - Acetylsalicylic acid+dipyridamole } \\
\text { (BTKbp) }\end{aligned}$ \\
\hline
\end{tabular}

Acetylsalicylic acid: aspirin.

ACCF/AHA, American College of Cardiology Foundation/American Heart Association; APT, antiplatelet therapy; BMS, bare-metal stent; BTKbp, below the knee bypass surgery; DAPT, dual APT; ESC, European Society of Cardiology; liBS, infrainguinal bypass surgery; NHG, National Healthcare Group; PAD, peripheral arterial disease.

At index time, $\beta$-blockers, ACE inhibitors, diuretics or glucose-modifying therapy were prescribed to $29 \%, 21 \%$, $23 \%$ and $21 \%$ of patients, respectively, (table 2). This was similar in patients not receiving APT or anticoagulants (table 4). Revascularisation was recorded for 102 individuals $(2.8 \%)$ (figure 4$)$. Patients received APT more often after revascularisation ( $88 \%$ vs $51 \%$ ), almost all as aspirin mono-APT $(55 \%)$ or as DAPT $(38 \%)$. P2Y12 inhibitors were mostly dispensed after revascularisation (44\% vs 20\%) (figure 3).

In total, $22.5 \%$ had a record of walking therapy. Within this group, $45 \%$ received aspirin concomitantly, $2.4 \%$ received concomitant P2Y12 inhibitors and $11 \%$ received DAPT. Patients in primary care were less likely to receive APT $(49 \%$ vs $60 \%)$. Patients who were ever in secondary care were more likely to receive APT ( $58 \%$ vs $48 \%$ ). Interestingly, prescription strategies varied delicately between specialties (table 5).

\section{DISCUSSION}

APT has been thoroughly embedded in guidelines regarding the medical treatment of atherosclerosis. Unfortunately, insight into adherence to these guidelines lacks. We found a profound gap between guideline recommendations and current practice for patients with PAD in the Netherlands. Almost half of all patients with newly diagnosed PAD did not receive any APT. Moreover, $33 \%$ of these patients received no antithrombotic therapy at all in any form. These findings are in line with other studies. ${ }^{21} 22$

As the cohort consists of Dutch patients, the Dutch GP guideline that was effective at the time of our study was considered to be the principal reference for GPs. Specialists were considered to refer to a combination of international and national guidelines. All guidelines stipulate the benefits of APT and primarily advise prescription of aspirin. Therefore, it seems unlikely that differences in guideline recommendations are the cause of this undertreatment.

It should be noted that in 2017 and 2019, the ESC in collaboration with the European Society for Vascular Surgery (ESVS) updated their guideline on the diagnosis and treatment of PAD. ${ }^{23}$ In 2019, the European Society for Vascular Medicine also published their guideline on PAD. ${ }^{24}$ The latter endorsed the recommendation first introduced by the ESC/ESVS concerning the treatment 
Table 2 Baseline characteristics

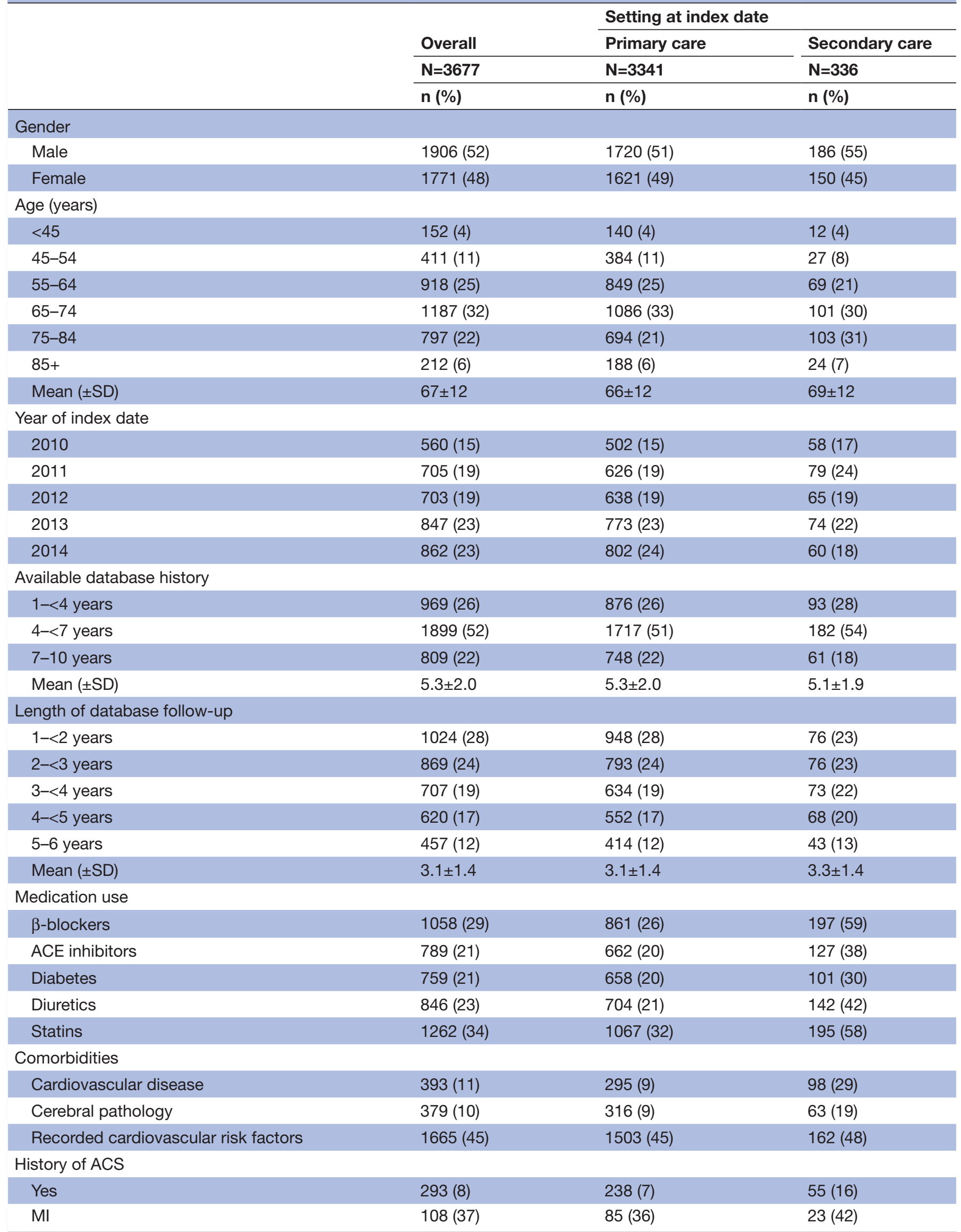




\begin{tabular}{|c|c|c|c|}
\hline & \multirow[b]{2}{*}{ Overall } & \multicolumn{2}{|c|}{ Setting at index date } \\
\hline & & Primary care & Secondary care \\
\hline & $N=3677$ & $N=3341$ & $\mathrm{~N}=336$ \\
\hline ICPC code K75 & $54(18)$ & $41(17)$ & $13(24)$ \\
\hline Time since MI (in years), mean $( \pm S D)$ & $2.7 \pm 2.3$ & $2.9 \pm 2.3$ & $2.0 \pm 2.4$ \\
\hline Other ACS & $185(63)$ & $153(64)$ & $32(58)$ \\
\hline No history of ACS & $3384(92)$ & $3103(93)$ & $281(84)$ \\
\hline
\end{tabular}

ACS, acute coronary syndrome; ICPC, International Classification of Primary Care; MI, myocardial infarction.

of patients with PAD requiring long-term oral anticoagulation. They both suggest considering treating this subset of patients with PAD with oral anticoagulation monotherapy. We found that $33 \%$ of patients with PAD did receive oral anticoagulation prescriptions (without any P2Y12 inhibitor or aspirin prescription). According to the aforementioned guidelines, these patients could be considered as adequately treated.

Previous studies showed similarly low APT prescription rates in patients with PAD. ${ }^{21}{ }^{22}$ In 'Long-Term Prognosis of Patients With Peripheral Arterial Disease, A Comparison in Patients With Coronary Artery Disease', Welten et al reported that only $40 \%$ of patients with PAD were prescribed aspirin in a cohort of 2730 patients. ${ }^{21}$ Although guidelines have uniform recommendations, we found that patients with recorded revascularisation received more APT prescriptions. This finding could indicate that the severity of the disease might influence prescription behaviour of physicians.

Since we excluded patients who had received APT or P2Y12 inhibitor prescriptions within the year preceding the index date, our results may underestimate the number of patients receiving adequate treatment. These medications could have been prescribed for another pathology and overlapped with the necessary treatment for their PAD diagnosis. As a result, there could have been considerably more patients with a new diagnosis of PAD within our timeframe who do receive adequate treatment. Nevertheless, this cannot fully explain the mismatch between guideline recommendations and current daily practice.

All patients diagnosed with PAD were assumed to have reports and thus symptomatic PAD. Because PAD screening is also indicated to identify or rule out diseases with PAD in their differential diagnosis, this could have led to the inclusion of asymptomatic patients, for whom the guidelines do not recommend APT. Again, this is unlikely to explain the large number of patients not receiving APT.

The REACH Registry showed that cardiologists were more prone to prescribe APT. ${ }^{22}$ In our study, $41 \%$ of all P2Y12 prescriptions by secondary care specialists were attributable to vascular specialists, like vascular internal medicine physicians, cardiologists or cardiothoracic surgeons, who treat most patients with PAD in the Netherlands. The complexity and high incidence of comorbidities in patients visiting vascular specialists might explain

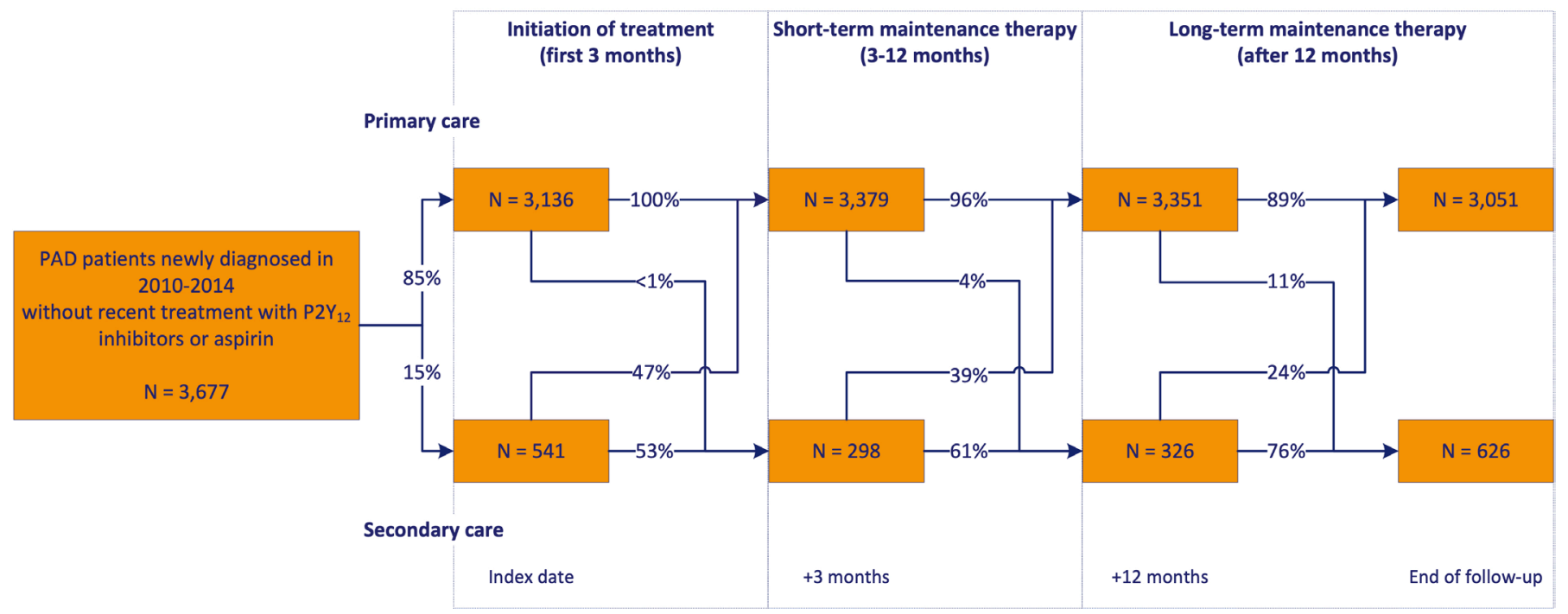

Figure 2 Flow of patients with PAD through primary and secondary care. PAD, peripheral arterial disease. 

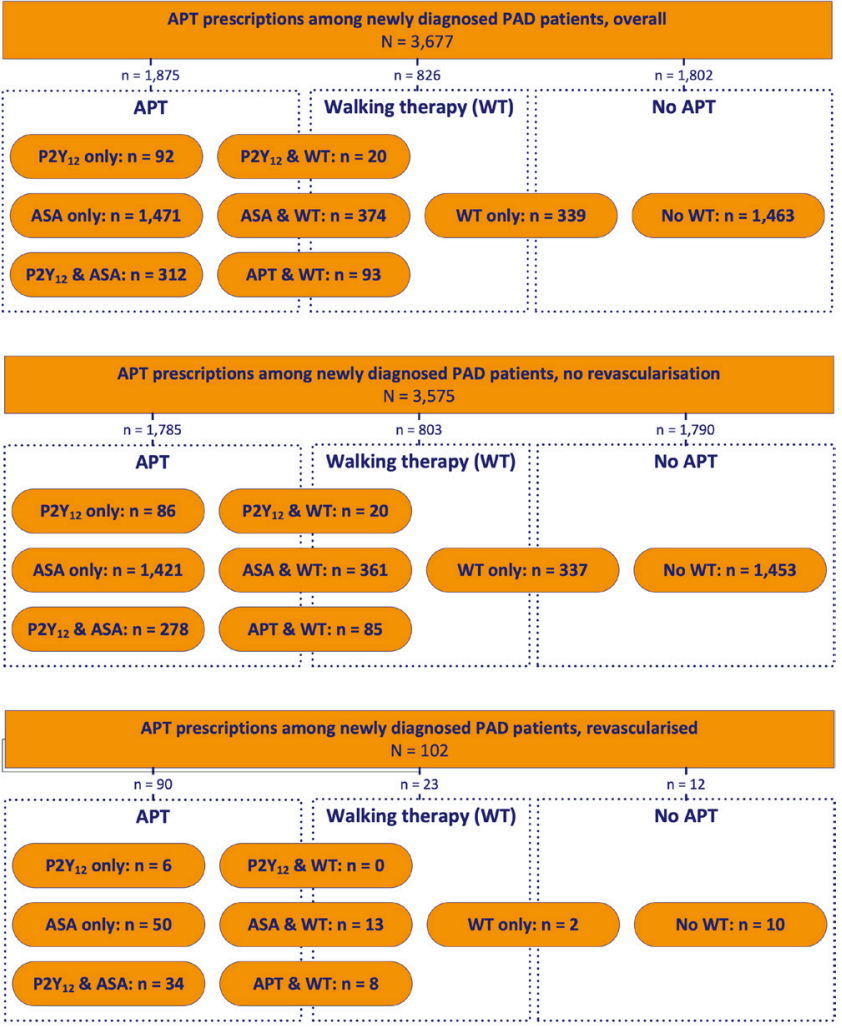

Figure 3 APT prescriptions among newly diagnosed patients with PAD $(A)$ revascularised, $(B)$ not revascularised (C). APT, antiplatelet therapy; ASA, acetylsalicylic acid; PAD, peripheral arterial disease.

heterogeneity in treatment plans. But as our data cannot provide in-depth insight into the patients' individual treatment plans, the impact of the heterogeneity of treatment strategies cannot be assessed.

Concomitant cardiovascular diseases might contribute to high thromboembolic risk. More aggressive APT strategies have been proposed for patients with carotid artery disease. These patients are also prone to $\mathrm{PAD}$ which might
Table 4 Cardiovascular medicine prescriptions within patients who did not receive any APT or anticoagulant therapy

\begin{tabular}{lll}
\hline Type & $\begin{array}{l}\text { In the year before } \\
\text { the index date }\end{array}$ & $\begin{array}{l}\text { In the year after } \\
\text { the index date }\end{array}$ \\
\hline ACE inhibitors & $19 \%$ & $21 \%$ \\
$\beta$-blockers & $22 \%$ & $22 \%$ \\
Statins & $31 \%$ & $37 \%$ \\
\hline
\end{tabular}

APT, antiplatelet therapy.

skew the number of prescriptions away from aspirin and towards P2Y12 inhibitors and other (more potent) APT agents. Patients in secondary care may be more likely to have multiple diseased vascular beds such as coronary artery or cerebrovascular pathology. In patients with PAD, polyvascular atherosclerotic disease is an independent risk factor for long-term cardiovascular death. ${ }^{25}$ Fortyeight per cent of patients in our study had a history of ACS; it is, therefore, feasible that polyvascular disease is a common phenomenon. Patients suffering from this type of conditions are regularly prescribed other types of anticoagulants. Although patients who did not receive APT were prescribed other anticoagulants agents two times as often as those who did receive APT (33 vs 14\%), it does not fully explain the undertreatment with APT.

The Dutch GP guideline advises aspirin in addition to supervised walking therapy for all patients with PAD. ${ }^{5}$ GPs might consider walking therapy as the first step for treating patients presenting with mild asymptomatic PAD. Nevertheless, our results do not reflect this. In total, $9.2 \%$ of all patients had a record of walking therapy as monotherapy accounting for $18.8 \%$ of patients who did not receive any APT. Therefore, the consideration of walking therapy as monotherapy does not appear to explain the shortcoming. Furthermore, our results indicate that patients with $\mathrm{PAD}$ are also undertreated regarding walking therapy

Table 3 Vitamin $\mathrm{K}$ antagonist and DOAC prescriptions

\begin{tabular}{|c|c|c|c|c|c|}
\hline & $\begin{array}{l}\text { Overall } \\
(\mathrm{N}=3677)\end{array}$ & $\begin{array}{l}\text { Patients with APT } \\
\text { (P2Y12 and aspirin) } \\
\text { (N=1875) }\end{array}$ & $\begin{array}{l}\text { Patients without APT } \\
\text { (P2Y12 and aspirin) } \\
\text { (N=1802) }\end{array}$ & $\begin{array}{l}\text { Patients with } \\
\text { P2Y12 } \\
\text { (N=404) }\end{array}$ & $\begin{array}{l}\text { Patients with } \\
\text { aspirin } \\
\text { ( } \mathrm{N}=1783)\end{array}$ \\
\hline & n (\%) & n (\%) & n (\%) & n (\%) & n (\%) \\
\hline DOACs or vitamin $\mathrm{K}$ antagonists & $850(23)$ & $256(14)$ & $594(33)$ & $107(26)$ & $206(12)$ \\
\hline Vitamin $\mathrm{K}$ antagonists & $812(22)$ & $245(13)$ & 567 (31) & $103(25)$ & $196(11)$ \\
\hline Acenocoumarol & $562(15)$ & $175(9)$ & $387(21)$ & $82(20)$ & $135(8)$ \\
\hline Phenprocoumon & $272(7)$ & $79(4)$ & $193(11)$ & $23(6)$ & $69(4)$ \\
\hline DOACs & $54(1)$ & $15(1)$ & $39(2)$ & $5(1)$ & $14(1)$ \\
\hline Apixaban & $10(<0.5)$ & $4(<0.5)$ & $6(<0.5)$ & $2(<0.5)$ & $3(<0.5)$ \\
\hline Dabigatran & $35(1)$ & $7(<0.5)$ & $28(2)$ & $2(<0.5)$ & $7(<0.5)$ \\
\hline Edoxaban & $0(0)$ & $0(0)$ & $0(0)$ & $0(0)$ & $0(0)$ \\
\hline Rivaroxaban & $13(<0.5)$ & $6(<0.5)$ & $7(<0.5)$ & $2(<0.5)$ & $6(<0.5)$ \\
\hline
\end{tabular}

APT, antiplatelet therapy; DOACs, direct oral anticoagulants. 


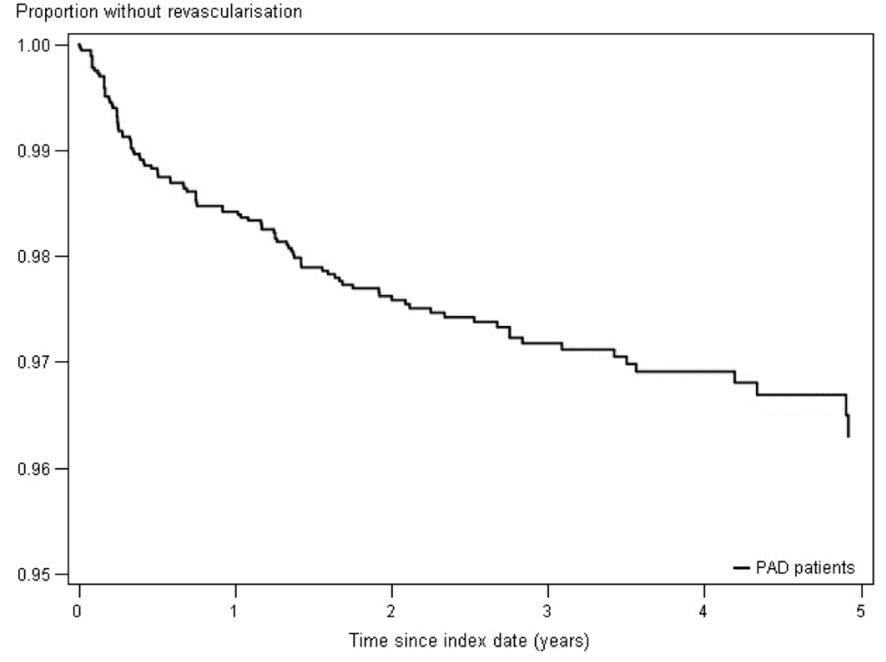

Figure 4 Proportion of patients without revascularisation among patients with PAD. PAD, peripheral arterial disease.

which is advised for all patients with PAD. Unfortunately, as walking therapy could only be extracted through free text searches, we cannot definitively conclude that there is undertreatment regarding walking therapy.

In the REACH Registry, $81.7 \%$ of patients within the PAD group received at least one type of APT and DAPT was prescribed to $14.9 \%$ of patients. ${ }^{22}$ In our study, only $51 \%$ of all patients received APT. DAPT was prescribed to $8.5 \%$ of all patients in our cohort. These differences may be explained by differences in inclusion. In the REACH Registry, patients were included if they met one or both of the following criteria: current IC with ankle-brachial index $<0.9$ or a history of IC with a previous and related vascular intervention, like angioplasty, stenting, atherectomy or peripheral arterial bypass graft. Therefore, patients in the REACH Registry PAD group could have more progressed PAD on average.

In contrast, in our cohort, only $3 \%$ of all patients underwent an intervention, indicating on average less advanced PAD and more patients receiving mono-APT, supervised walking as monotherapy or were treated with a watchful waiting strategy. Even though these groups are not exactly

Table 5 APT prescriptions per specialism

\begin{tabular}{lcccc}
\hline Specialism & All APT & P2Y12 & Aspirin & DAPT \\
\hline General practitioner & $88 \%$ & $83 \%$ & $89 \%$ & $85 \%$ \\
Surgeon & $4.5 \%$ & $2.7 \%$ & $4.9 \%$ & $1.2 \%$ \\
Cardiologist & $2.7 \%$ & $6.9 \%$ & $1.9 \%$ & $6.9 \%$ \\
$\begin{array}{l}\text { Cardiopulmonary } \\
\text { surgeon }\end{array}$ & $0.0 \%$ & $0.0 \%$ & $0.0 \%$ & $0.0 \%$ \\
Internist & $1.0 \%$ & $0.8 \%$ & $1.1 \%$ & $0.2 \%$ \\
Neurologist & $0.3 \%$ & $1.1 \%$ & $0.1 \%$ & $0.2 \%$ \\
Other specialist & $3.0 \%$ & $5.0 \%$ & $2.6 \%$ & $6.7 \%$ \\
Other & $0.3 \%$ & $0.3 \%$ & $0.3 \%$ & $0.2 \%$ \\
\hline APT, antiate & & & & \\
\hline
\end{tabular}

APT, antiplatelet therapy; DAPT, dual APT. matching, both findings reflect the low rates of APT prescriptions and might partially explain them. Early-stage PAD might be a reason for physicians to delay APT, thereby disregarding guideline recommendations. Overcoming the inability to gather information on the stage of the disease might elucidate this limitation within both studies.

The swift increase of statin prescriptions over the last decades might have led GPs to believe that no additional treatment is warranted. Undertreatment might also, in part, be explained by patients switching medications due to side effects. This would have influenced our data only slightly because our data are based on prescriptions, as the side effects would only become apparent after using the medication, at least one prescription would be registered. Also, our data did not contain information about the time between diagnosis and start of medication.

Within our study, PAD diagnosis was based on ICPC and GP examination codes in combination with free search terms. Not all GPs will have equally used uniform terminology and meticulous file management. Underestimation or overestimation of new PAD diagnoses can be caused by typographical errors $(5 \%)$ or underregistration. Although our strategy attempted to correct for typographical errors, vague language or incomplete recording can have led to missed cases. Also, the number of patients returning to primary care may be underestimated due to such blind spots. Our estimation of patients receiving walking therapy is also probably limited by this.

Ours is the first cohort study covering the treatment strategies for patients with newly diagnosed PAD on a national scale. It offers the opportunity to evaluate the concordance of healthcare daily practice with guideline recommendations. Investigating possible causes of and solutions for the mismatch between recommendations and real practice can expedite the incorporation of (new) guideline recommendations into daily practice.

Our analysis reveals the importance of getting a better understanding of the PAD health system and patient journey in practice throughout the world. The patient journey and APT prescription within both primary and secondary care settings may serve as an indicator of the quality of patient care. They reflect the adherence to evidence-based guidelines and influence PAD prognosis. These are the first data to give an insight into the 'realworld' use of APT throughout the present-day healthcare journey of patients with newly diagnosed PAD in the Netherlands. Comparison with current practice in other countries and the development of a broad consensus on treatment strategy will ameliorate PAD treatment and facilitate optimal treatment for patients with PAD.

\section{CONCLUSION}

Current practice in the Netherlands does not concur with guideline recommendations on APT for patients with newly diagnosed PAD. At least $33 \%$ of these patients do not receive any antithrombotic therapy. Improvement of APT prescription and thereby improved (secondary) CVE 
prevention is warranted. We advise physicians to inquire if patients with PAD receive APT and if not, to investigate the reason to omit prescribing these medicines.

\section{Author affiliations}

${ }^{1}$ Department of Vascular Surgery, University Medical Center Utrecht, Utrecht, The Netherlands

${ }^{2}$ PHARMO Institute, PHARMO Institute for Drug Outcomes Research, Utrecht, The Netherlands

${ }^{3}$ Department of Vascular Medicine, University Medical Centre Utrecht, Utrecht, The Netherlands

${ }^{4}$ Julius Center for Health Sciences and Primary Care, University Medical Center Utrecht, Utrecht University, Utrecht, Utrecht, The Netherlands

${ }^{5}$ Department of Epidemiology \& Data Science, Amsterdam Public Health Research Institute, Amsterdam UMC (Location VUmc), Amsterdam, The Netherlands

Correction notice This article has been corrected since it was first published. Name for Dr Gert J de Borst has been corrected.

Contributors ARTB - conception and design of the manuscript and interpretation of the data; drafting and revising the work critically for intellectual content. EH and IDB-acquisition and analysis of the data and revising the work for consistency. FLJV, MLB and GJdB — revising the work critically for intellectual content. RMCH— content guarantor, acquisition and analysis of the data.

Funding The data were granted by AstraZeneca.

Competing interests None declared.

Patient consent for publication Not required.

Ethics approval The database research with anonymous data did not require Institutional Review Board or ethics committee approval. We upheld the ethical standards of the Declaration of Helsinki.

Provenance and peer review Not commissioned; externally peer reviewed.

Data availability statement Data are available upon reasonable request. Data may be obtained from a third party and are not publicly available. Data available upon request at PHARMO.

Supplemental material This content has been supplied by the author(s). It has not been vetted by BMJ Publishing Group Limited (BMJ) and may not have been peer-reviewed. Any opinions or recommendations discussed are solely those of the author(s) and are not endorsed by BMJ. BMJ disclaims all liability and responsibility arising from any reliance placed on the content. Where the content includes any translated material, BMJ does not warrant the accuracy and reliability of the translations (including but not limited to local regulations, clinical guidelines, terminology, drug names and drug dosages), and is not responsible for any error and/or omissions arising from translation and adaptation or otherwise.

Open access This is an open access article distributed in accordance with the Creative Commons Attribution Non Commercial (CC BY-NC 4.0) license, which permits others to distribute, remix, adapt, build upon this work non-commercially, and license their derivative works on different terms, provided the original work is properly cited, appropriate credit is given, any changes made indicated, and the use is non-commercial. See: http://creativecommons.org/licenses/by-nc/4.0/.

\section{ORCID iDs}

Aarent RT Brand http://orcid.org/0000-0002-2467-8161

Eline Houben http://orcid.org/0000-0002-9173-3335

Frank L J Visseren http://orcid.org/0000-0003-3951-5223

\section{REFERENCES}

1 Criqui $\mathrm{MH}$, Langer RD, Fronek A, et al. Mortality over a period of 10 years in patients with peripheral arterial disease. $N$ Engl J Med 1992;326:381-6.

2 Criqui MH, Aboyans V. Epidemiology of peripheral artery disease. Circ Res 2015;116:1509-26.

3 Dhaliwal G, Mukherjee D. Peripheral arterial disease: epidemiology, natural history, diagnosis and treatment. Int J Angiol 2007;16:36-44.

4 Van Dis IBJ, Vaartjes I, Visseren FLJ, et al. Hart- en vaatziekten in Nederland 2015. Den Haag: Hartstichting, 2015.

5 Bartelink ML SH, Boutens EJ, Hooi JD. NHG-Standaard Perifeer arterieel vaatlijden (Eerste herziening). Huisarts Wetenschap 2003;46:848-58.
6 Hirsch AT, Haskal ZJ, Hertzer NR, et al. ACC/AHA 2005 practice guidelines for the management of patients with peripheral arterial disease (lower extremity, renal, mesenteric, and abdominal aortic): a collaborative report from the American association for vascular Surgery/Society for vascular surgery, Society for cardiovascular angiography and interventions, Society for vascular medicine and biology, society of interventional radiology, and the ACC/AHA Task force on practice guidelines (writing Committee to develop guidelines for the management of patients with peripheral arterial disease): endorsed by the American association of cardiovascular and pulmonary rehabilitation; National heart, lung, and blood Institute; Society for vascular nursing; transatlantic Inter-Society consensus; and vascular disease Foundation. Circulation 2006;113:e463-654.

7 Norgren L, Hiatt WR, Dormandy JA. Inter-Society consensus for the management of peripheral arterial disease (TASC II). Int Angiol 2007;26:82-157.

8 European Stroke Organisation, Tendera M, Aboyans V, et al. Esc guidelines on the diagnosis and treatment of peripheral artery diseases: document covering atherosclerotic disease of extracranial carotid and vertebral, mesenteric, renal, upper and lower extremity arteries: the task force on the diagnosis and treatment of peripheral artery diseases of the European Society of cardiology (ESC). Eur Heart J 2011:32:2851-906.

9 American College of Cardiology Foundation, American Heart Association Task Force, Society for Cardiovascular Angiography and Interventions, et al. 2011 ACCF/AHA focused update of the Guideline for the management of patients with peripheral artery disease (updating the 2005 guideline). Vasc Med 2011;16:452-76.

10 Sigvant B, Wiberg-Hedman K, Bergqvist D, et al. A populationbased study of peripheral arterial disease prevalence with special focus on critical limb ischemia and sex differences. J Vasc Surg 2007;45:1185-91.

11 Meijer WT, Hoes AW, Rutgers D, et al. Peripheral arterial disease in the elderly: the Rotterdam study. Arterioscler Thromb Vasc Biol 1998;18:185-92.

12 Dormandy J, Heeck L, Vig S. The natural history of claudication: risk to life and limb. Semin Vasc Surg 1999;12:123-37.

13 van Haelst STW, Koopman C, den Ruijter HM, et al. Cardiovascular and all-cause mortality in patients with intermittent claudication and critical limb ischaemia. Br J Surg 2018;105:252-61.

14 Antithrombotic Trialists' (ATT) Collaboration, Baigent C, Blackwell $\mathrm{L}$, et al. Aspirin in the primary and secondary prevention of vascular disease: collaborative meta-analysis of individual participant data from randomised trials. Lancet 2009;373:1849-60.

15 CAPRIE Steering Committee. A randomised, blinded, trial of clopidogrel versus aspirin in patients at risk of ischaemic events (CAPRIE). CAPRIE Steering Committee. Lancet 1996;348:1329-39.

16 Peeters Weem SMO, van Haelst STW, den Ruijter HM, et al. Lack of evidence for dual antiplatelet therapy after endovascular arterial procedures: a meta-analysis. Eur J Vasc Endovasc Surg 2016;52:253-62

17 van Herk-Sukel MPP, van de Poll-Franse LV, Lemmens VEPP, et al. New opportunities for drug outcomes research in cancer patients: the linkage of the Eindhoven cancer registry and the PHARMO record linkage system. Eur J Cancer 2010;46:395-404.

18 Herings R, Pedersen L. Pharmacy-based Medical Record Linkage Systems. In: Strom B, Kimmel S, Hennessy S, eds. Pharmacoepidemiology. 5 edn. John Wiley \& Sons, Ltd, 2012: 270-86.

19 International classification of primary care. Available: https://www. nhg.org/themas/artikelen/icpc

20 Methodology WCCfDS. Anatomical therapeutic chemical (ATC) classification system 2011. Available: https://www.whocc.no/atc/ structure_and_principles/ [Accessed 31 Oct 2017].

21 Welten GMJM, Schouten O, Hoeks SE, et al. Long-term prognosis of patients with peripheral arterial disease: a comparison in patients with coronary artery disease. J Am Coll Cardiol 2008;51:1588-96.

22 Bhatt DL, Steg PG, Ohman EM, et al. International prevalence, recognition, and treatment of cardiovascular risk factors in outpatients with atherothrombosis. JAMA 2006;295:180-9.

23 Aboyans V, Ricco J-B, Bartelink M-LEL, et al. Editor's Choice - 2017 ESC Guidelines on the Diagnosis and Treatment of Peripheral Arterial Diseases, in collaboration with the European Society for Vascular Surgery (ESVS). Eur J Vasc Endovasc Surg 2018;55:305-68.

24 Frank U, Nikol S, Belch J, et al. ESVM guideline on peripheral arteria disease. Vasa 2019;48:1-79.

25 van Kuijk J-P, Flu W-J, Welten GMJM, et al. Long-term prognosis of patients with peripheral arterial disease with or without polyvascular atherosclerotic disease. Eur Heart J 2010;31:992-9. 
